\title{
Mapeamento de áreas propensas ao risco ambiental no Município de Santa Rita (PB) pelo uso de Sistema de Informações Geográficas
}

Mapping of areas propose to the environmental risk in the Municipality of Santa Rita (PB) by the use of a Geographical Information System

PEREIRA $^{1}$, F. M. S.; ARAÚJO ${ }^{2}$, S. H.; CUNICO ${ }^{3}$, C. florizamaria36@gmail.com

\begin{abstract}
Resumo
As variáveis que envolvem o estudo de riscos ambientais são muitas e complexas, como importante ferramenta pedagógica nos estudos sobre esta temática tem-se o mapeamento de áreas propensas a ele pelo uso de Sistema de Informações Geográficas (SIG). O município de Santa Rita localizado no estado da Paraíba, entre os anos de 2002 e 2011 registrou duas ocorrências de enchentes de acordo com Plano Diretor de Proteção Civil, assim o presente trabalho teve como objetivo principal mapear as áreas propensas ao risco ambiental do município. A metodologia aplicada associa as cartografias digitais de clinografia, drenagem e setores censitários do Censo Demográfico de 2010 do Institulo Brasileiro de Geografia e Estatística (IBGE). Como resultado principal tem-se que metade do município de Santa Rita $(49,1 \%)$ encontra-se em situação de insegurança ambiental "Muito Baixo" e "Baixo" localizados majoritariamente ao norte da cidade, já as maiores intensidades de risco ambiental "Muito Alto" e "Alto" (34,2\%) localizam-se mais ao sul.
\end{abstract}

Palavras-Chave: Risco ambiental, SIG, mapeamento, Santa Rita.

\begin{abstract}
As the variables that involves the study of environmental risks are many and complex, an important pedagogical tool in the studies on this subject is the mapping of prone areas with the use of Geographic Information System (GIS). The municipality of Santa Rita located in the state of Paraíba, between 2002 and 2011, recorded two floods occurrences in accordance with the Civil Protection Master Plan, as well as the main objective of the work is mapping the prone areas to environmental risk of the municipality. The methodology applied associates the digital cartographys of clinography, drainage and the census sectors of the 2010 Demographic Census of the Brazilian Institute of Geography and Statistics (BIGE). As a main result, half of the municipality of Santa Rita $(49.1 \%)$ is in a situation of "Very Low" and "Low" environmental insecurity, mostly at the north of the city, as well as greater environmental risk intensities "Very High "and" Hight "(34.2\%) are located at the south.
\end{abstract}

Keywords: Environmental risk, GIS, mapping, Santa Rita.

\section{INTRODUÇÃO}

O estudo sobre risco constantemente é objeto de interesse da comunidade acadêmica, podendo-se destacar entre as principais obras desta temática o livro "Sociedade de risco", do sociólogo alemão Ulrich Beck, publicado em 1986, porém, a exploração deste conceito voltado às questões ambientais possui história recente que para Dagnino e Junior (2007, p. 50)

\footnotetext{
${ }^{I}$ Floriza Maria da Silva Pereira, Departamento de Engenharia Civil e Ambiental, Universidade Federal da Paraíba, João Pessoa-PB, Brasil.

${ }^{2}$ Silvânia Henrique de Araújo, Departamento de Engenharia Civil e Ambiental, Universidade Federal da Paraíba, João Pessoa-PB, Brasil.

${ }^{3}$ Camila Cunico, Departamento de Geociências, Universidade Federal da Paraíba, João Pessoa-PB, Brasil.
} 
está associada a importantes temas elencados pelo meio acadêmico como a interdisciplinaridade e o papel da ciência e tecnologia no mundo. Para Castro, Peixoto e Pires (2005, p. 12) a categoria de risco é uma análise relacionada a incertezas, prejuízos, e perdas que pode ser de origem natural, tecnológica e social. De acordo com Veyret e Meschinet de Richemond (2007) os riscos ambientais são resultado das relações entre riscos naturais e riscos devido aos processos naturais intensificados pela atividade antrópica e pela ocupação territorial. Mendonça (2002 apud DUBOIS-MAURY, J; CHALINE, C., 2009, p.130) ao tratar dos riscos associados ao espaço urbano indica que "A vulnerabilidade urbana aos riscos, sejam eles endógenos ou exógenos, é uma noção complexa porque pode ter conteúdos humanos, econômicos, patrimoniais, tecnológicos e organizacionais que se diversificam no espaço e no tempo [...]”.

Pode-se perceber com base nas informações supracitadas que as variáveis que envolvem o estudo de riscos ambientais são muitas e complexas, assim, como importante ferramenta pedagógica nos estudos sobre esta temática tem-se o mapeamento de áreas propensas a ele, utilizado por muitas vezes para análise e avaliação em diferentes recortes geográficos, por exemplo. Neste sentido, a Lei 12.608 de 10 de abril de 2012 que institui a Política Nacional de Proteção à Defesa Civil (PNPDEC); dispõe sobre o Sistema Nacional de Proteção e Defesa Civil (SINPDEC) e o Conselho Nacional de Proteção à Defesa Civil (CONPDEC) no art. $6^{\circ}$, inciso IV incube à União apoiar os "Estados, o Distrito Federal e os Municípios no mapeamento das áreas de risco, nos estudos de identificação de ameaças, suscetibilidades, vulnerabilidades e risco de desastre e nas demais ações de prevenção, mitigação, preparação, resposta e recuperação; [...]”.

Com o intuito de combinar diversos mapas e dados georreferenciados surgiu na década de 60 no Canadá o Sistema de Informações Geográficas (SIG), possível, devido a evolução da tecnologia de Informática ao associar técnicas matemáticas e computacionais para o tratamento de informações geográficas em ambiente computacional (INPE, 2001). Alves (2007 e 2013) e Cunico (2013) são alguns dos autores que usam deste sistema em seus trabalhos para definir áreas de risco. A metodologia aplicada envolve associar cartografias digitais de clinografia, drenagem e setores censitários do Censo Demográfico do Instituto Brasileiro de Geografia e Estatística (IBGE).

Em 2015, o IBGE apresentou o panorama da urbanização brasileira que englobou as concentrações populacionais com mais de 100 e 300 mil habitantes, entre os municípios que se adequam a estes quantitativos tem-se João Pessoa, capital do Estado da Paraíba, com 148, $93 \mathrm{~km}^{2}$ de 163, 54 km² de sua área densamente urbanizada, ou seja, com população acima de 
300 mil habitantes. As manchas urbanas que compõe a área definida acima comportam além da capital outros três municípios Bayeux, Cabedelo e Santa Rita.

Com base no Plano Diretor de Proteção Civil: Redução de Riscos e Desastres, elaborado pelo Governo da Paraíba em conjunto com a Secretaria do Estado da Infraestrutura e Gerência Executiva de Defesa Civil de 2012, entre os anos de 1993 e 2011 o município de Santa Rita apresentou os meses de fevereiro e junho como os mais atingidos por excesso de chuva, além de compartilhar junto a outras 13 cidades que compunham a mesorregião da Mata Paraibana ${ }^{1}$, entre os anos de 2002 e 2011, a ocorrência de 25 desastres com duas ocorrências de enchentes apenas no município de Santa Rita. De acordo com o mesmo plano, o Estado da Paraíba enfrenta como principais problemas de desastres o incremento ou intensa redução das precipitações hídricas que variam ao longo do estado em regime sazonal.

Desta forma, o presente trabalho teve como objetivo principal mapear as áreas propensas ao risco ambiental do município de Santa Rita, localizado no estado da Paraíba com os seguintes objetivos específicos caracterizar o objeto de estudo, analisar os resultados cartográficos das variáveis elencadas e identificar os setores censitários em situações de maior insegurança ambiental. O trabalho estrutura-se em introdução, metodologia, resultados e discussões, conclusões e referências.

\section{METODOLOGIA}

A metodologia aplicada no trabalho baseia-se nos estudos desenvolvidos por Alves (2007 e 2013) e Cunico (2013) que associam as cartografias digitais, pelo Sistema de Informações Geográficas (SIG), de clinografia, drenagem e setores censitários do IBGE pela propriedade denominada álgebra de mapas. A hipótese que orienta esta metodologia é de que os setores de clinografia inferior a $3 \%$ ou superior a $30 \%$, próximos a cursos d'água e/ou reservatórios e demograficamente adensados então propensos a um grau de risco ambiental elevado. A seguir será apresentada a metodologia para obter cada um dos resultados cartográficos utilizados para definir o risco ambiental.

\footnotetext{
${ }^{1}$ A partir de 2017 o Instituto Brasileiro de Geografia e Estatística (IBGE) redefiniu as divisões geográficas brasileiras, anteriormente elas eram denominadas de Mesorregiões e Microrregiões que tinham como fundamento os aspectos físico-naturais dos territórios. Porém, em decorrência do crescente processo de urbanização foram delimitadas as Regiões Geográficas Intermediárias e Imediatas que levam em consideração as Metrópoles, Capitais Regionais e centros urbanos. Com base na atual divisão a Região Geográfica Intermediária de João Pessoa é composta por 57 municípios e a Imediata por 22 (IBGE, 2017).
} 


\subsection{Clinografia}

Para obter a cartografia digital de clinografia recorreu-se a plataforma digital denomidada de Topotada, Banco de Dados Geomorfométricos do Brasil, que oferece o Modelo Digital de Elevação (MDE) em cobertura nacional. Em seguida, foi selecionada a quadrícula que inclui o município de Santa Rita e esta foi espacializada em software de geoprocessamento, vale salientar que os dados fornecidos pela plataforma foram previamente tratados. Após este procedimento definiu-se como intervalos de interesse para o trabalho as clinografias, inferior a 3\% e superior a 30\%. Com base em Alves (2007 e 2013) a clinografia superior a 30\% indica que a geomorfologia local está predisposta à ocorrência de movimentos de massa, deslizamentos e intensos processos erosivos, porém diante da realidade do município e com base na metodologia de Cunico (2013) se incluiu as áreas de clinografia inferior a $3 \%$, pois estas caracterizam-se por planícies fluviais que comumente sofrem com inundações.

\subsection{Drenagem}

De acordo com Alves (2007 e 2013) as áreas próximas, até 50 metros, de cursos d'água e reservatórios estão susceptíveis às doenças de veiculação hídrica e outras associadas à contaminação de água, além de enchentes e inundações. Em termos do processamento digital, obteve-se os dados da rede de drenagem e dos reservatórios (açudes) do município de Santa Rita pela plataforma digital da Agência Executiva de Gestão das Águas do Estado da Paraíba (AESA) disponibilizada no Geoportal. Em seguida estas informações foram georreferenciadas e pela ferramenta denominada de buffer definiu-se o raio de 50 metros de distância dos corpos hídricos, foram obtidos dois resultados cartográficos que compõem a drenagem, são eles: buffer de 50 metros para cursos d'água e buffer de 50 metros para reservatórios.

\subsection{Risco ambiental}

Com base na metodologia definida pelos mesmos autores pode-se realizar a associação das cartografias digitais anteriores a malha digital dos setores censitários definidos pelo Censo Demográfico de 2010 do IBGE, os dados do Censo foram obtidos na plataforma digital do instituto e assim como os demais dados foram espacializados em ambiente digital. A associação dos elementos que compõem o risco ambiental só foi possível devido a propriedade denominada de álgebra de mapas que permite a coexistência ou sobreposição espacial das cartas temáticas. Nesta etapa, utilizou-se do método estatístico descritivo 
denominado de quantis para definir os intervalos que determinam a intensidade do risco ambiental. Este método consiste em dividir a amostra em n-partes iguais, ou seja, se n é igual a cinco o primeiro quartil equivale a $40 \%$ da amostra abaixo da mediana, o segundo corresponde a $20 \%$ da amostra abaixo da mediana, o terceiro corresponde a mediana, o quarto equivale a $20 \%$ da amostra acima da mediana e o quinto corresponde a $40 \%$ da amostra acima da mediana, assim tem-se a abrangência de todos os valores que formam a amostra. Com base neste tratamento e de acordo com os princípios da cartografia temática que indicam a determinação de até cinco classes devido a capacidade de percepção das cores pelo olho humano, definiu-se o risco ambiental em cinco intensidades (classes) distintas, são elas: "Muito baixo", "Baixo", "Médio", “Alto", e "Muito Alto".

\section{RESULTADOS E DISCUSSÃO}

\subsection{Caracterização da área de estudo}

Santa Rita está situada na Região Imediata de João Pessoa e compõem a Região Metropolitana de João Pessoa (RMJP) no estado da Paraíba (Fig. 1), de acordo com o Instituto Brasieleiro de Geografia e Estatística em 2017 possuía uma área de unidade territorial igual a 706, 38 km², com população estimada em 2018 de 135.807 habitantes e densidade demográfica no ano de 2010 igual a 165,52 hab $/ \mathrm{km}^{2}$. No ano de 2016 o salário médio mensal dos trabalhadores formais equivalia a 1,7 salários mínimos e no ano de 2010 $44,6 \%$ da população tinha rendimento nominal mensal per capita de até $1 \frac{1}{2}$ salário mínimo. Em termos de economia, o município teve no ano de 2015 PIB (Produto Interno Bruto) per capita igual a $\mathrm{R} \$ 16.156$, 46. O município de Santa Rita tem cerca de 95\% do seu território constituído de zona rural e apenas 5\% de zona urbana. 


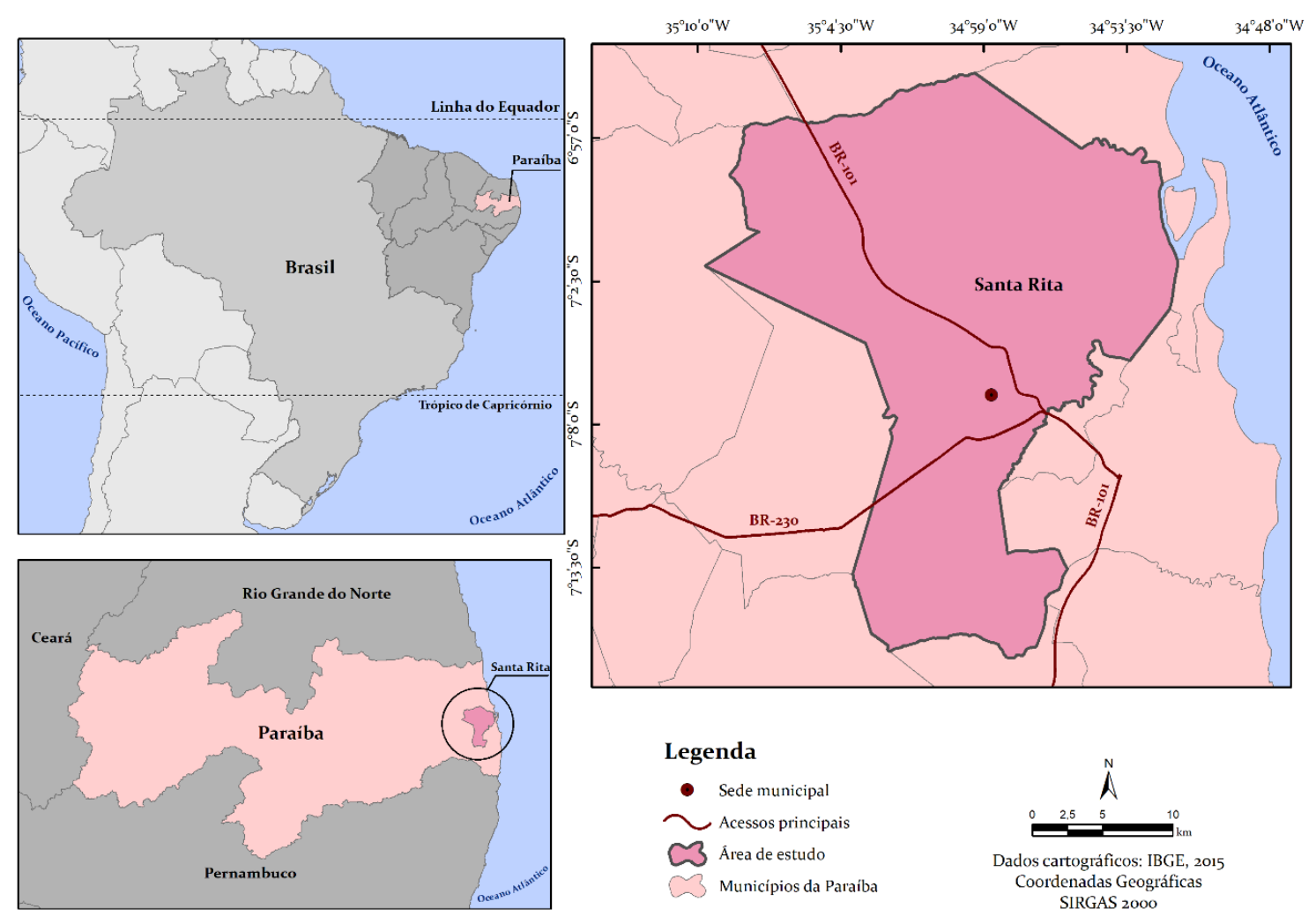

Figura 1: Mapa de localização da área de estudo. Fonte: IBGE, 2015. Org.: Autora, 2018.

\subsection{Aspectos físico-naturais}

Em termos das características físico-naturais tem-se que a cidade de acordo com a Prefeitura Municipal de Santa Rita, possui três bacias hidrográficas em seu território: Bacia Hidrográfica do Rio Gramame (103,11 km²), Bacia Hidrográfica do Rio Miriri $\left(103,72 \mathrm{~km}^{2}\right)$ e a Bacia Hidrográfica do Rio Paraíba, especificamente a Sub-Bacia do Baixo Curso do Rio Paraíba (520,4 km²), Fig. 2. O município de Santa Rita encontra-se na Bacia Sedimentar Pernambuco-Paraíba ou Bacias do Saliente Oriental, composta pela zona sedimentar costeira de Pernambuco, Paraíba e zona sedimentar costeira oriental do Rio Grande do Norte (MARINHA, 2011, p.128). Com base em Furrier (2007, p.25) a cidade está inserida na SubBacia Alhanda e possui como principais formações geológicas o Grupo Barreiras e Formação Beberibe (NEVES; et al, 2009). 

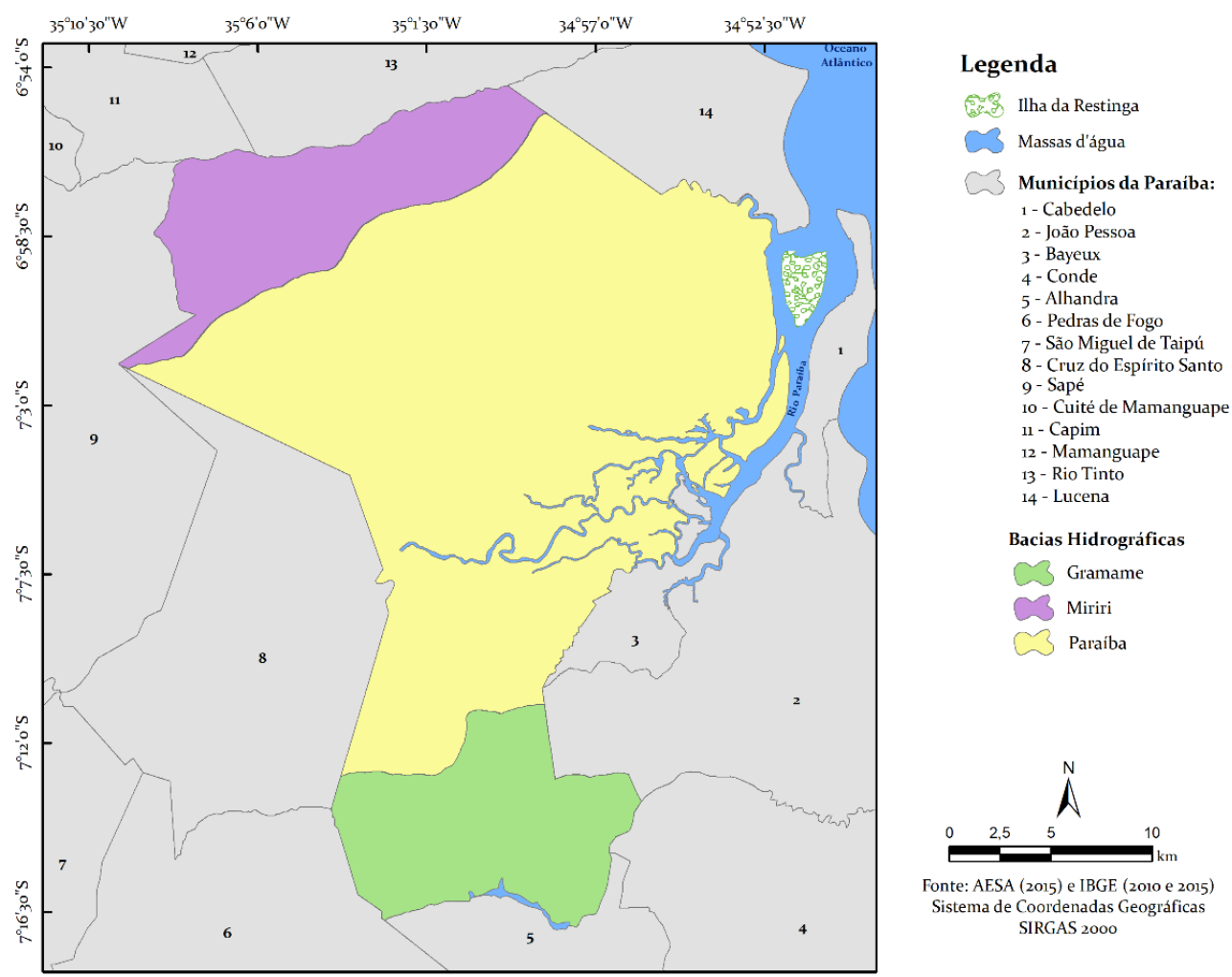

Fonte: AESA (2015) e IBGE (2010 e 2015) Sistema de Coordenadas Geográficas SIRGAS 2000

Figura 2: Bacias hidrográficas localizadas no município de Santa Rita. Fonte: AESA (2010) e IBGE (2010). Org.: Autora, 2018.

Segundo Furrier; et al (2006, p.65) os Tabuleiros Litorâneos sobre os quais Santa Rita se situa apresentam cotas que variam de 49 a $177 \mathrm{~m}$ com cotas altimétricas máximas localizadas imediatamente ao sul do Rio Miriri e mínimas na margem sul do Rio Paraíba até o vale do Rio Gramame.

Em termos do tipo de vegetação, a Bacia Hidrográfica do Rio Gramame de acordo com Silva; et al (2002 apud SEPLAN, 1997, p. 122) teve sua vegetação nativa substituída pelas culturas intensivas da cana-de-açúcar, abacaxi, mandioca, restando apenas alguns trechos de Mata Atlântica e seus ecossistemas. Já a Bacia Hidrográfica do Rio Miriri tem como vegetação natural a Floresta Atlântica e ecossistemas associados como restinga, cerrados e manguezais (PARAÍBA, 2006). O Baixo Curso do Rio Paraíba possui vegetação similar às anteriores e caracteriza-se também pelo desmatamento da Mata Atlântica para o cultivo da cana-de-açúcar. Em Santa Rita, no ano de 1586 foi criado o primeiro engenho de cana-de-açúcar denominado de Engenho Real Tibiri localizado na várzea do Rio Paraíba (SILVA, 2003, p. 77).

De acordo com Moreira (2002) as médias pluviométricas variam entre $1800 \mathrm{~mm}$ a 2000 mm, com clima As’ ou quente úmido segundo a classificação de Koppen. Possui clima 
definido como Tropical Chuvoso com verão seco e período de chuvas entre fevereiro e outubro, destacando-se os meses de fevereiro e junho.

\subsubsection{Clinografia}

A partir da metodologia apresentada anteriormente pode-se construir a carta temática da clinografia do município (Fig. 3), necessária para definir as áreas propensas ao risco ambiental.

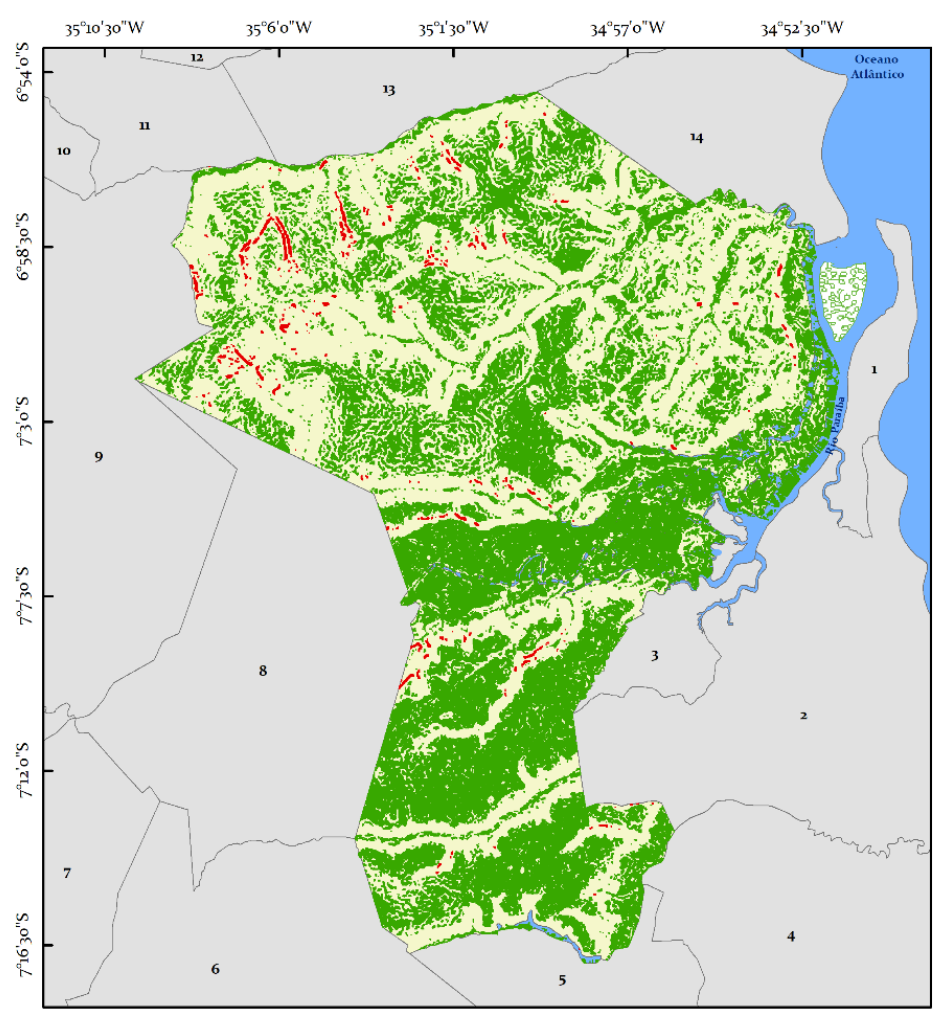

Legenda
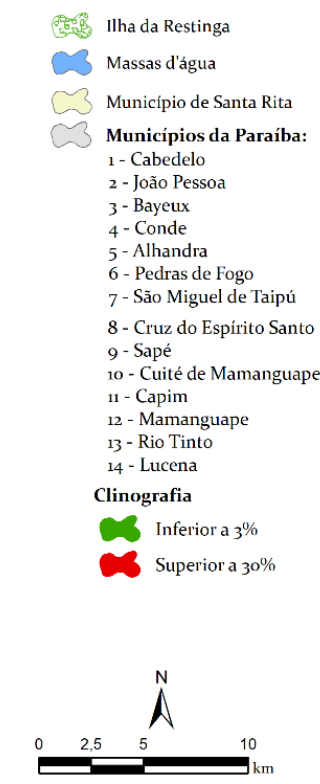

Fonte: AESA (2015) e IBGE (2010 e 2015) Sistema de Coordenadas Geográficas SIRGAS zooo

Figura 3: Clinografia da área de estudo. Fonte; AESA (2015) e IBGE (2010 e 2015). Org.; Autora, 2018.

Santa Rita tem 93,5\% de seu território com clinografia inferior a 3\% e, 6,5\% superior a 30\%, de acordo com o estudo da área as cotas de maior clinografia encontram-se na Bacia Hidrográfica do Rio Miriri com significativa presença de cursos d'água. Esta região possui sedimentos não consolidados do período Quaternário (sedimentos de praia, dunas e aluviões) e arenitos quatzozos e/ou calcífero.

\subsubsection{Drenagem}

Foram produzidas duas cartografias digitais para caracterização do município de Santa Rita, buffer para reservatórios ou açudes (Fig. 4) e buffer para cursos d'água (Fig. 5). 

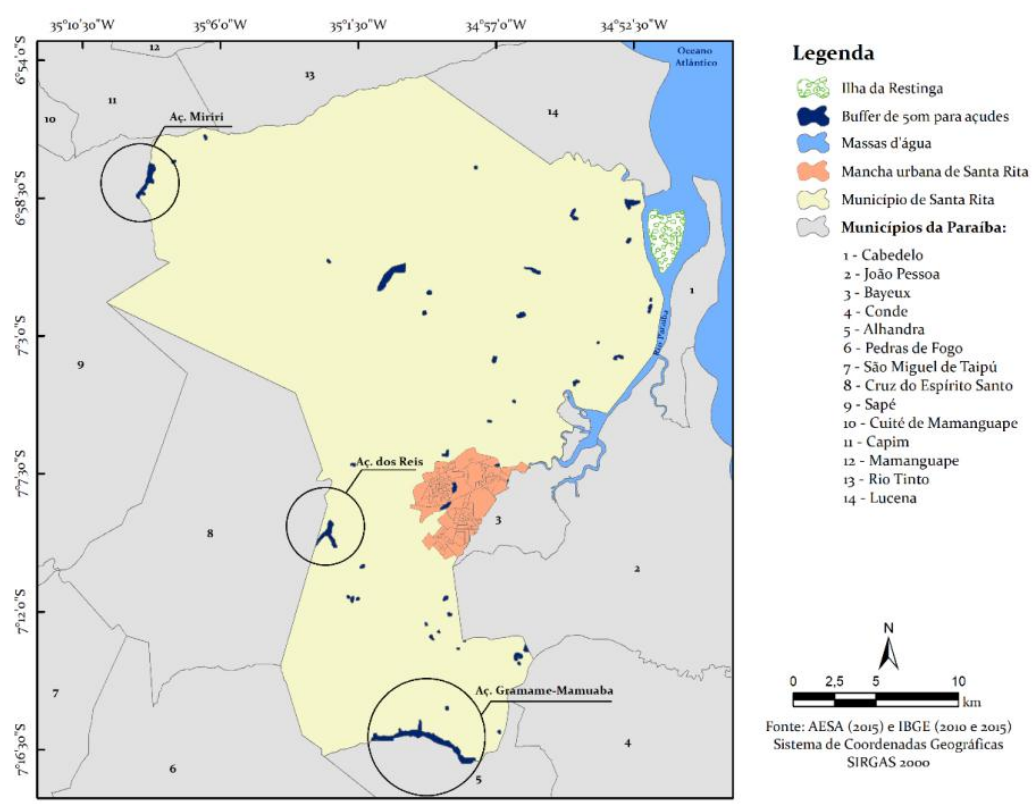

Figura 4: Buffer de $50 \mathrm{~m}$ para reservatórios da área de estudo. Fonte: AESA (2015) e IBGE (2010 e 2015).

Org.: Autora, 2018.

Entre os açudes de destaque tem-se o Gramame-Mamuaba, este reservatório de acordo com a AESA, no ano de 2018 tem capacidade de armazenamento de aproximadamente 57 milhões de metros cúbicos e abastece as 13 cidades que formam a Região Metropolitana de João Pessoa. Os rios que formam a drenagem principal (Fig. 5) de Santa Rita possuem diversos usos, entre eles o abastecimento humano, animal, irrigação, pesca e carcinicultura.
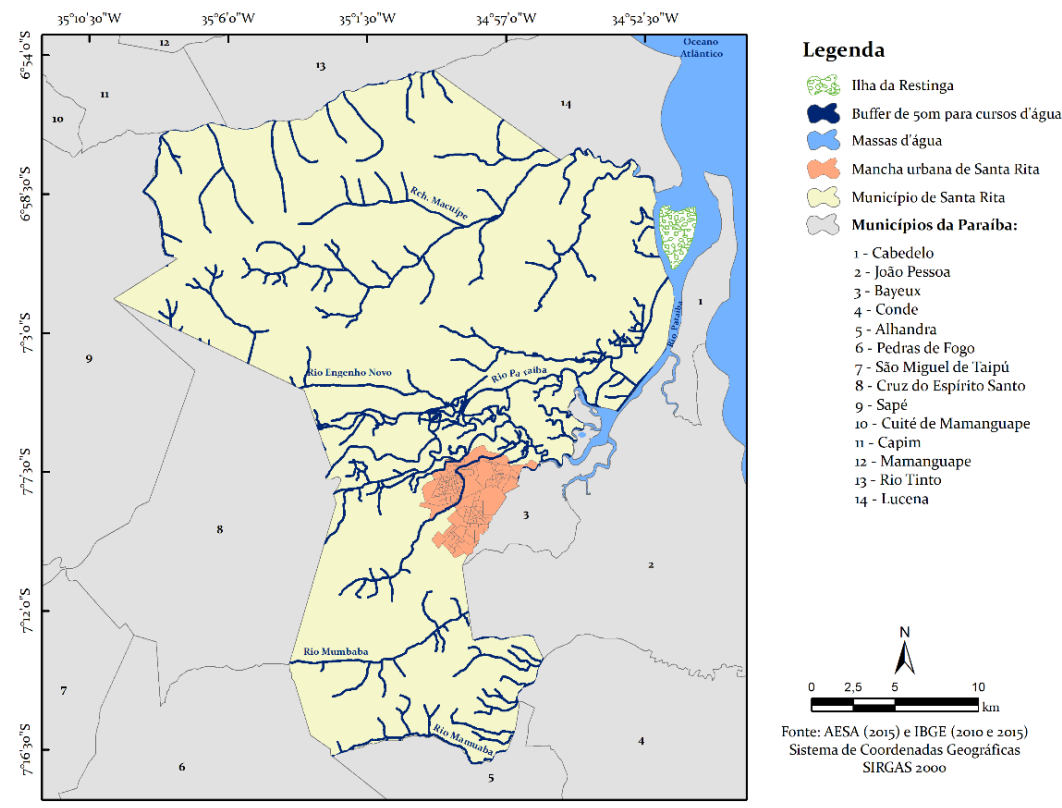

Figura 5: Buffer de 50m para cursos d'água da área de estudo. Fonte: AESA (2015) e IBGE (2010 e 2015).

Org.: Autora, 2018. 


\section{3 Áreas propensas ao risco ambiental}

Por fim, obteve-se o mapeamento das áreas propensas ao risco ambiental (Fig. 6) do município de Santa Rita definido pelos intervalos das classes da Tabela 1.

Tabela 1: Classificação do risco ambiental pelo intervalo de classes. Fonte: AESA (2015) e IBGE (2010 e 2015). Org.: Autora, 2018

\begin{tabular}{cc}
\hline Classificação do risco ambiental & Intervalos das classes $(\%)$ \\
\hline Muito Baixo & 0 a 6,36 \\
Baixo & 6,37 a 37,72 \\
Médio & 37,73 a 61,10 \\
Alto & 61,11 a 80,64 \\
Muito Alto & 80,65 a 100,00 \\
\hline
\end{tabular}
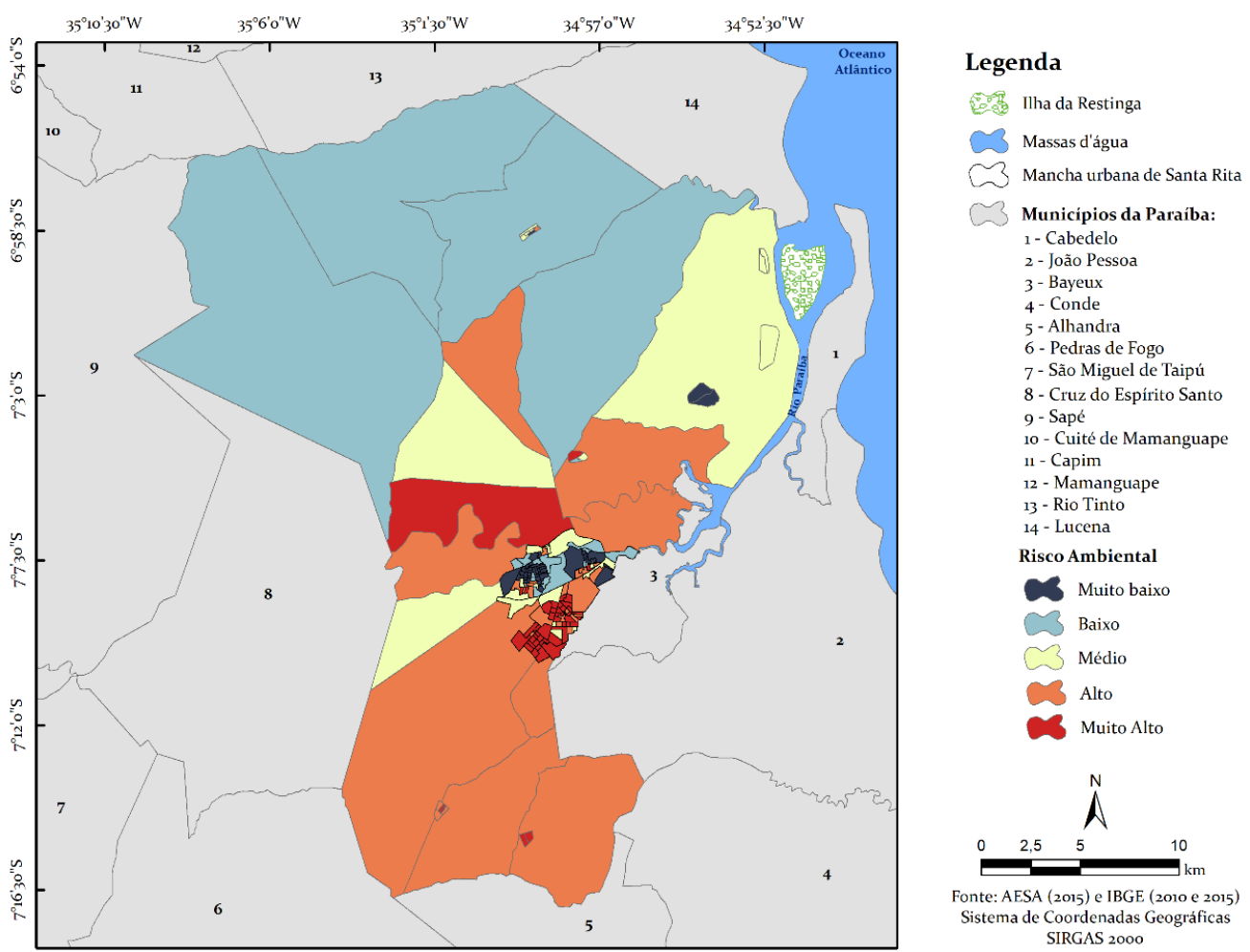

Figura 6: Mapeamento de áreas pronpensas ao risco ambiental da área de estudo. Fonte: AESA (2015) e IBGE (2010 e 2015). Org.: Autora, 2018.

Já o Gráfico 1 mostra a porcentagem dos riscos ambientais pela área do município de Santa Rita. 
Gráfico 1- Distribuição das classes de risco ambiental no município de Santa Rita - PB (\%).Fonte: AESA (2015) e IBGE (2010 e 2015). Org.: Autora, 2018

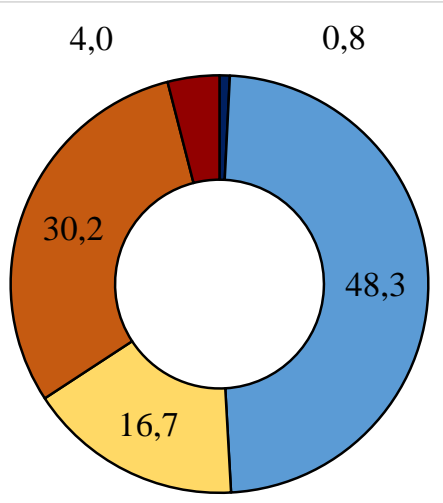

$\square$ Muito Baixo $\square$ Baixo $\square$ Médio $\quad \square$ Alto $\square$ Muito Alto

Ao analisar os resultados para o risco ambiental tem-se que metade do município de Santa Rita $(49,1 \%)$ encontra-se em situação de insegurança ambiental "Muito Baixo" e "Baixo" localizados majoritariamente ao norte da cidade, já as maiores intensidades de risco ambiental "Muito Alto" e "Alto" (34,2\%) localizam-se mais ao sul da cidade. Estes resultados se devem às características geomorfológicas e hidrológicas do município. Apesar da região ao norte possuir cotas altimétricas elevadas como informado anteriormente, seus rios e açudes não se encontram entre os corpos hídricos de enfoque da Agência Executiva de Gestão das Águas do Estado da Paraíba (AESA), ao sul tem-se os principais cursos d'água do litoral paraibano além de declividade inferior a 3\%, e superior a 30\% ao sul do Rio Paraíba, este espaço geográfico apresenta conflitos de distintas origens, destacando-se o uso da água, agriculturas intensas, poluição hídrica, abastecimento humano, entre outros. Acrescido a estes fatores esta região se encontra bastante adensada, tanto que nesta se situa a mancha urbana do município.

Por estes motivos as áreas indicadas como de maior insegurança ambiental devem ser prioridade dos planos de gerenciamento de riscos e desastres já que um ambiente propício ao risco ambiental e a presença antrópica coexistem. A partir deste mapeamento e estudo minucioso junto a população e pesquisa em demais fontes pode-se definir medidas preventivas e de proteção que atenuem ou evitem desastres. 


\section{CONCLUSÕES}

Desta forma, conclui-se que a metodologia aplicada fornece resultados satisfatórios e coerentes com a realidade do município de Santa Rita, mas enfatiza-se que apenas o uso desta ferramenta não é suficiente para definir diretrizes de um plano de gerenciamento de riscos e desastres. Indica-se que sejam elaborados estudos minuciosos do recorte geográfico junto a população e equipe técnica qualificada.

O fator social apesar de não ser considerado no mapeamente destas áreas deve ser levado em consideração devido interferência antrópica sobre o meio natural e os danos que fenômenos naturais podem causar ao não preparar a população aos excessos de chuva característicos da área de estudo.

\section{REFERÊNCIAS}

DAGNINO, R. S.; JUNIOR, S. C. Risco Ambiental: conceitos e aplicações. Rio Claro: Rev. de Climatologia e Estudos de Paisagem., vol. 2, n.2. jul/dez 2007. 50 p. p. 50-84.

VEYRET, Y.; MESCHINET DE RICHEMOND, N. Os riscos: o homem como agressor e vítima do meio ambiente. São Paulo: Contexto, 2007. p. 23-79.

MENDONÇA, F. Geografia, geografia física e meio ambiente: uma reflexão a partir da problemática socioambiental urbana. Mato Grosso do Sul: Revista Anpege, vol. 5, 2009. 130 p. p. $123-134$.

BRASIL. Lei 12.608 de 10 de abril de 2012. Institui a Política Nacional de Proteção à Defesa Civil (PNPDEC); dispõe sobre o Sistema Nacional de Proteção e Defesa Civil (SINPDEC) e o Conselho Nacional de Proteção à Defesa Civil (CONPDEC). Brasília, 2012.

INPE; CÂMARA G.; DAVIS, C. Introdução: Por que geoprocessamento?. São José dos Campos:2001.p. $1-5$.

ALVES, H. P. F. Desigualdade ambiental no município de São Paulo: análise da exposição diferenciada de grupos sociais a situações de risco ambiental através do uso de metodologias de geoprocessamento. Revista Brasileira de Estudos da População, São Paulo, v. 24, n. 2, p. 301-316, jul/dez. 2007.

ALVES, H. P. F. Análise da vulnerabilidade socioambiental em Cubatão-SP por meio da integração de dados sociodemográficos e ambientais em escala intraurbana. Revista Brasileira de Estudos da População, Rio de Janeiro, v. 30, n. 2, p. 349-366, jul/dez. 2013.

CUNICO, C. Do risco à adaptação: a identificação da vulnerabilidade socioambiental de Curitiba: 2013. 269 f. Geografia (Doutorado em Geografia) - Universidade Federal do Paraná, Curitiba, 2013. 
IBGE. Instituto Brasileiro de Geografia e Estatística. Divisão Regional do Brasil em Regiões Geográficas Imediatas e Regiões Geográficas Intermediárias. Rio de Janeiro: IBGE, 2017.

PARAÍBA. Gerência Executiva de Defesa Civil. Plano diretor de proteção civil: redução de riscos e desastres. João Pessoa: 2012, 70 f.

MARINHA, E. G. A. Bases geológicas e geomorfológicas das organizações espaciais do município de João Pessoa. Recife: 2011. 318f. Geociências (Doutorado em Geologia sedimentar e ambeintal) - Universidade Federal de Pernambuco. Recife, 2011.

FURRIER, M.Caracterização geomorfológica e do meio físico da folha João Pessoa - 1: 100.000. São Paulo: 2007. p. 21 - 26. Geografia (Doutorado em Geografia) - Universidade de São Paulo. São Paulo, 2007.

NEVES, B. B. B.; et al. Novos dados geológicos e geofísicos para caracterização geométrica e estratigráfica da sub-bacia de Alhandra (sudeste da Paraíba). São Paulo: Revista do Instituto de Geociências - USP, vol. 9, n. 2. jun 2009. p. 63 - 87.

FURRIER, M.; et al. Geomorfologia e tectônica da Formação Barreiras no Estado da Paraíba. São Paulo: Revista do Instituto de Geociências - USP, vol. 6, n. 2, 65 p. p. 61 - 70, out. 2006.

SILVA, T. C.; et al. Planejamento dos Recursos Hídricos na Bacia Hidrográfica do Rio Gramame: Uma Bacia Litorânea do Nordeste Brasileiro. Brasil: RBRH - Revista Brasileira de Recursos Hídricos, vol. 7, n. 4, out/dez 2002, 122 p. p. 121 - 134.

PARAÍBA. Agência Executiva de Gestão das Águas do Estado da Paraíba (AESA). Plano Estadual de Recursos Hídricos - PERH. João Pessoa: 2006.

SILVA, L. M. T. Nas margens do Rio Paraíba do Norte. João Pessoa: Logepa, vol. 2, jul/dez 2003, 77 p. p. $74-80$.

MOREIRA, E. O estudo geográfico das cidades. Revista Cidades, v. 1, n. 2, 2004, p. 277 314.

Recebido em: 13/04/2019

Aceito para publicação em: 25/05/2019 